\title{
Workforce Diversity And Organizational Communication: Analysis Of Human Capital Performance And Productivity
}

Ephraim A. Okoro, Howard University, USA

Melvin C. Washington, Howard University, USA

\begin{abstract}
The twenty-first century organizations are increasingly becoming multicultural workplaces for communication. This paper explores recent literature on the increasing global influence of workforce diversity and its affect on workplace communication. It provides a model for the discussion of the opportunities and challenges of diversity in the workplace. The paper then provides an analytical framework that guides readers with practical ideas that can assist them in their endeavors to effectively communicate in a globally diverse work environment. The paper stresses that effective communication in a diverse workforce ensures a high level of performance and productivity for human and intellectual capital and provides business organizations a competitive advantage in their expanded markets and in the global economy.
\end{abstract}

Keywords: Workforce Diversity; Organizational Communication; Global Economy; Cultural Differences; Intellectual Capital

\section{INTRODUCTION}

s the workforce becomes increasingly global and progressively more culturally diverse, people in
organizations are challenged to communicate more effectively interpersonally, interculturally, and in
groups. Authors (Lauring, 2011, \& Devoe, 1999) noted that as a result of the rise of internationalized business environment and global competitiveness, the managing of human diversity has become a challenging daily routine task for a major part of business communities. In discussing strategies for business communication, Bovee and Thill (2008) emphasized that effective interpersonal and group communication is essential for success in today's corporations and organizations because of the growing trend of workforce diversity and intercultural business relationships. Some studies (Ferraro, 2001; Gupta, 2008; Jandit, 2003) have emphasized the impact of communication in a diverse workplace and how it affects productivity and overall performance of a business. Broadly speaking, Mulkeen (2008) describes workplace diversity as all the differences in age, gender, sexual orientation, education, cultural background, religion, and life experience. The author noted that today's workforce does not exist in a vacuum or is isolated from the marketplace, but that it is part of an emerging international business environment where effective organizational communication is vital for sustainable growth. In fact, Ober (2006) explained that effective communication, both internally and externally, is essential for any organization wishing to excel in today's internationally competitive corporate environment and global business and competitive advantage would not be achievable without effective business communication.

\section{Diversity In Business Organizations}

Recent studies have attributed workforce diversity to the increased globalization of the twenty-first century, which has increased the mobility of people across nations as well as the interdependence of organizations. With globalization comes the challenge of communication among people with different cultural and racial backgrounds. For example, Martin and Nakayama (2007) note that for many people, communication encounters with diverse people from different ethnic, race, and national backgrounds occur most frequently in the workplace. Similarly, 
Clive (2007) and Hunt (2011) argued that workplaces are the only sites at which individuals from diverse cultures convene and collaborate, and thus refreshes and broadens the relevancy of an organization. In addition, Sadri and Tran (2002) found that improvements in supervisor-subordinate communication would prompt workplaces to manage diversity and cultural differences by encouraging integration and equality in the workplace. These authors recommend two strategies for accomplishing better supervisor-subordinate communication - managing personal growth and mentoring new employees. Grimes and Richards (2003) and Gupta (2008) pointed out that with the U.S. population becoming increasingly diverse over the past two decades, effective intercultural communication has become the top priority facing diverse work environments; hence, cultural diversity can be advantageous or detrimental for organizations depending on the nature and structure of organizations' members' communication. Significantly, Hannay \& Fretwell (2011) and Deveale \& Manea (2007) urge that by expanding avenues for communication and providing ongoing feedback, workplaces can establish a culture that honors, values, and appreciates those who work in their environments. Other scholars have determined that the performance and productivity of human capital in the global marketplace depends, to a large extent, on the effectiveness of business communication, which includes employees' ability to encode, decode, and analyze messages contextually (Ferraro, 2001, \& Nagourney, 2008). Similarly, in a study, Beaner (2007) identified and described the importance of interpersonal communication, intercultural sensitivity, business practice differences, and nonverbal communication competence as essential for effective organizational communication. The author stressed that effective human performance in group or team-oriented environments depends largely on the understanding of messages, the sharing of meanings, interpersonal adjustments, and adaptations. Clearly, the productivity of a diverse workforce would be almost impossible to increase without effective communication and other forms of human interactions.

Given the widespread impact of globalization and internationalization, workplace diversity in all forms of organizations, including higher education, is now a fact of life and a trend that will continue for a long time. In an earlier study, Cox \& Blake (1991) pointed out that workforce demographics in the United States and many other countries indicate that workforce management would be on the agendas of many forward-looking corporate leaders. It was further noted that the ability to manage a diverse workforce provides an opportunity for competitive advantage through improved decision-making and cross-cultural negotiation.

Researchers have noted that ignoring the implications of workforce diversity can affect productivity and performance as well as undermine the overall goal business performance. For example, Kanu (2008) reported that Goldman Sachs has more than 30,000 employees representing about 160 nationalities. Consistent with other business organizations in the United States and abroad, Goldman Sachs' discussions around diversity have extended from domestic to international issues. Indeed, as the world economy continues to expand and attract more competitors, business scholars and practitioners have embarked on extensive study of intercultural and organizational communication and its implications across academic disciplines (Jandt, 2003; Tuleja, 2008; Hannay \& Fretwell, 2011). Consistent with the preceding statement, Bovee \& Thill (2008) buttresses that the United States has been a nation of immigrants from the beginning and that the trend has continued with the result that increased emphasis has been placed on human and intercultural communications. Recent immigrants comprise over half of all U.S. workforce. According to the U.S. Census Bureau, by the middle of the twenty-first century, the United States will cease to have a majority race. Non-Hispanic whites will comprise about one-half of the total population, while Hispanics will account for about one-quarter of the country's population. African Americans will grow to about 13 percent, while Asian Americans are projected to become about 8 percent of the nation's citizenship. Out of more than 278 million people living in the U.S., over 33 million speak Spanish, while more than 10 million speak another European language and more than eight million speak an Asian language. Additionally, several scholars see a multicultural workforce as a natural outgrowth of business globalization, which complicates the way people from different backgrounds in organizational and learning contexts communicate in writing, verbally, and nonverbally (Ferraro, 2001; Friedman, 2005; Giroux, 2004). Hence, organizations are now escalating their diversity initiatives as they measure the benefits of multi-cultural and diverse organizations.

Current trends in domestic and global workplaces indicate the need for intercultural competence, and research evidence strongly suggests the need for organizations to prepare their human capital for the globalized economy in which business success is largely determined by the ability to communicate effectively across cultures. Bowes (2008) exposes the presence of globalization and its impact on the current generation of employees, indicating that it has become a means for creating a workplace that genuinely welcomes employees from diverse 
countries into organizational settings. Diversity is then viewed as a key means to strengthen the human and intellectual capital of businesses through effective communication and negotiation. In a comparative analysis, Bovee and Thill (2008) reconciled the advantages and disadvantages offered by a diverse workforce and argue that diversity has continued to attract the attention of business practitioners and entrepreneurs. It is noted that diversity is fast becoming a key factor for recruitment, retention, productivity, and sustained competitiveness of organizations. Friedman (2005) and Gupta (2008) concur that a diverse workforce can yield a unique advantage by employing new ideas and communication skills and also providing a diversity of thoughts that result in better business solutions and decision-making.

\section{Linking Workplace Diversity to Organizational Performance Improvement}

Cadrain (2008) discusses why companies are embracing diversity and argues that encouraging diversity is a positive motivational tool that can attract and retain the best employees as well as increase the level of organizational competitiveness. Hansen (2003) estimated that corporations in the United States spend \$8 billion annually on diversity initiatives and related issues. Many of these business organizations have identified the significance of maintaining a workforce that truly reflects the diverse nature of the contemporary society of the twenty-first century.

Both practitioners and researchers point to education and communication as the key for corporations to transform the behavior of their employees toward embracing and accepting diversity. In addition, a diverse workforce that effectively communicates can take advantage of the strengths, talents, and differences in the workplace by eliminating communication barriers and developing their employees to their fullest potential (DeVeale \& Manea, 2007), increasing productivity, facilitating innovation, and enabling the resolution of problems (Davis, 2000), allowing better service to diverse customers (Thomas \& Ely, 1996), and taking advantage of the opportunity to enhance their future growth and development for a competitive advantage (Roberson \& Park, 2007).

\section{Diversity in the Workplace: A Strategic Imperative}

We live in an age of globalization and knowledge economy. Business organizations and academic institutions will be successful only to the extent that they are able to embrace and encourage workforce diversity. By ensuring that their workplace is significantly diverse and that minority groups are respected, appreciated, and valued, the learning environments (universities and colleges) will be able to harness the collective knowledge of their faculty and staff. As Friedman and Amoo (2002) noted, the collective knowledge of organizations, including academic institutions, can be enhanced by including people with different experiences, trainings, and racial/cultural backgrounds. Marketers and marketing consultants agree that critical ideas for new products have been suggested by subcultures. Foods, such as tacos, tortillas, pita, kasha, etc., did not originate in mainstream America, but were first popular with sub-cultural groups. The same is true of much of the educational milestones that have become widely known and respected. The higher education environments and business establishments (profit and not-forprofit organizations) need new ideas to thrive and the best way to ensure a steady flow of innovation and the realization of these objectives will stem from hiring and retaining employees and faculty from diverse backgrounds, race, and nationalities. As Schwartz (2001) explained, a homogenous workforce is not likely to come up with creative solutions to facing domestic and global markets, but empathetic marketing is very effective. Firms that hire employees similar to their customers will become more successful because these employees will be able to identify the special problems faced by their customers and will be able to come up with ideas for new products that best satisfy women, minorities, and the disabled. The U.S. Census Bureau (2001) estimated that Hispanics alone will spend about $\$ 1$ trillion a year by 2010 .

\section{Costs and Benefits of Workforce Diversity: Benefits}

Over the years, research by scholars (Abbasi, Hollman, 1991; Anderson, 1993) point out that the collective diversity among business organizations and academic institutions is one of the great strengths of America's workforce and has helped increase the country's competitive advantage. Preserving and sustaining diversity of workplace is critically important if the United States, and indeed the global society, expects to serve the urgent development needs of democratic societies. 
For example, both domestic and global academic institutions share a common philosophy, born of experience, that diversity in their student bodies, faculty, and staff is important in order to fulfill their fundamental educational mission and live up to their objectives of providing equal and quality education. A number of studies (Garvin, 1993; U.S. Census Bureau, 2002; Florida \& Gates, 2001) emphasize that diversity in higher education enriches the teaching and learning experience of students and faculty and creates an academic environment that is conducive to building supportive and life-long relationships. Furthermore, education within a diverse setting prepares students to become good citizens in an increasingly complex, pluralistic global society and fosters mutual respect and teamwork.

With the increasing mobility of the workforce in the twenty-first century, higher education is facing a diverse work environment, both for faculty and student population. Striving to recruit, effectively manage, and maintain a diverse workforce is an important goal in order to ensure that the right combination of skills and competencies are available at university campuses. As Campbell (2008) noted, the second half of the twentieth century witnessed quite a dramatic shift in the nature of white-collar employment from lifetime tenure, often in a very hierarchical work structure to a new model defined by flatter organizations, job insecurity, shorter tenures, declining attachment between employer and employee, and contingent workers. Other studies (Abbasi, 1991; Amott \& Mathane, 1991) indicated that in recent years managing employment relations has become an issue of huge strategic importance as higher education and businesses struggle to respond to the pace of change in management and administrative system and working practices.

Furthermore, domestic and global organizations are designed to create products (goods, services, or ideas) that cater for diverse consumers and to ensure that there are benefits for their various multicultural stakeholders. Therefore, the development and management of human activities, whether in higher education or in industries associated with the transformation of resources into finished goods and services, or of transferring knowledge from faculty to students, is of critical importance for the sustainable growth and profitability of business enterprises around the world. As Ferrell, Hirt, and Ferrell (2008) pointed out, organizations as diverse as Dell Computer, Campbell Soup, UPS, and public hospitals share a number of similarities relating to how they transform resources into goods and services for consumers, but it is important that individuals who are involved in the production and distribution of services are managed effectively and that communication among them is open and interactive.

\section{Negative Effects/Costs of Workforce Diversity}

Even though in this ever-changing multi-cultural environment, good communication is increasingly important, intercultural communication creates a daunting challenge in the workplace. Managing diversity is more than simply acknowledging differences in people. Flatley, Rentz and Lentz (2012) noted that it is crucial that the business communicator is able to adapt to quickly changing responsibilities and work relationships. Increased globalization of business, immigration, the aging of the "Baby Boomers," the escalation of women in the workforce, and the changing educational environment are all fueling these trends. According to Bovee and Thill (2008), "today's increasingly diverse workforce encompasses a wide range of communication challenges, including skills, traditions, backgrounds, experiences, outlooks, and attitudes toward work, all of which can affect communication in the workplace (p. 64). Organizations face the challenge of coexisting with business partners and the community. Managers and supervisors face the challenge of motivating and creating harmony among their workers. In addition, (Devoe (1999) and Esty, et.al (1995) found that managers may be faced with losses due to personnel and work productivity, as well as negative attitudes and behaviors that serve as barriers to effective organizational diversity. In 2007, the Equal Employment Opportunity Commission filed more than 80,000 lawsuits related to diversity issues as organizations that ignore diversity are more likely to face lawsuits, negative feelings, and lowered morale (Lieber, 2009). Therefore, to be effective in interacting across cultural boundaries, organizations need to be sensitized to the values of understanding, appreciating, and respecting human and cultural differences.

\section{CONCLUSION}

The workplace of the twenty-first century, including higher education, is changing rapidly. Faculty and administrators who occupy senior and high-powered academic positions are diverse in age, gender, and race. Staff and faculty responsibilities, skills, training, and the tasks they perform in their various units/departments and 
universities are changing as a result of demographic differences. Additionally, domestic and global organizations are now designed to create products (goods, services, or ideas) for their diverse consumers and to ensure that there are benefits for their diverse stakeholders. In evaluating the role of operations management in acquiring the resources necessary to create goods and services, it is critically important to understand the importance of workforce diversity and effective communication in achieving the objectives of organizations and academic institutions.

Studies of recent years (Weaver, 2001; Crosette, 2001; Lewis, 2002) indicate that there is a correlation between diversity in the workplace and organizations' results and sustainability.

An evaluation of the costs and benefits of studies on workforce diversity in organizations indicated conflicting results, but there is consistency among researchers that effective communication - especially interculturally - is critically significant to sustain a healthy work environment that encourages outstanding performance and workforce retention. Strategic and well-focused diversity initiatives and intercultural communication workshops are recommended as an essential part of organizational orientations and retreats.

\section{AUTHOR INFORMATION}

Ephraim A. Okoro, $\mathrm{PhD}$ is an assistant professor of business communication and marketing at Howard University. His research interests probe the interface between intercultural communication and workforce diversity in the context of globalization. He teaches business communication, management/ marketing communications, and principles of marketing. Address correspondence to Dr. Ephraim Okoro, Department of Marketing, School of Business, Howard University, 2600 - Sixth Street, NW, Washington, D.C. 20059; Corresponding author. E-mail: eaokoro@howard.edu.

Melvin C. Washington, $\mathrm{PhD}$ is an assistant professor of business and management communication at Howard University. He is the core course coordinator for the business communication program in the School of Business, Department of Marketing. His research focuses on intercultural communication, organizational communication, and critical pedagogy. Address correspondence to Melvin C. Washington, Howard University School of Business, 2600 $6^{\text {th }}$ Street N.W., Washington, D.C. 20059; E-mail: m_c_washington@ howard.edu.

\section{REFERENCES}

1. Abbasi, S.M. \& Hollman (1991). Managing Cultural Diversity: The challenge of the 90s Records Management. Records Management Quarterly, 25, 24-32.

2. Anderson, J. A. (1993). Thinking about diversity. Training and Development, 49, 59-60.

3. Ammott, T. L. \& Matthaie (1991). Race, gender, and work. South End Press: Boston.

4. Bovee, C. L., \& Thill, J. V. (2008). Business communication today (9th ed.). Boston: Prentice Hall.

5. Bowes, B. (2007, December). The business case for workplace diversity. CMA Management, 81(8), 14-16. Retrieved June 24, 2011, from ABI/INFORM Global. (Document ID: 1430001721).

6. $\quad$ Cadrain, D. (2008). Sexual equity in the workplace. HR Magazine, 53(9), 44-48, 50.

7. Clive Muir. (2007). Communicating diversity at work. Business Communication Quarterly, 70(1), 80-82. Retrieved June 17, 2011, from ABI/INFORM Global. (Document ID: 1219373241).

8. Cox, T.H. \& Blake, S. (1991). Managing cultural diversity: Implications for organizational competitiveness. Academy of Management Executive, 5(3), 45-46.

9. Crossette, Barbara (2001). "Living in a World Without Women." The New York Times, November 4, Section 4, 1-5.

10. Davis, S. (2000). Minority execs want an even break, Workforce, 799(4), 50-55.

11. DeVeale, C., \& Manea, L. (2007, December). Companies embrace power of diversity. Canadian HR Reporter, 20(22), 14-15.

12. Devoe, Deborah. (1999). Managing a diverse workforce. San Mateo, CA: InfoWorld Media Group.

13. Esty, Katharine, Richard Griffin, and Marcie Schorr-Hirsh (1995). Workplace diversity. A manager's guide to solving problems and turning diversity into a competitive advantage. Avon, MA: Adams Media Corporation. 
14. Ferraro, G. P. (2001). Global brains: Knowledge and competencies for the twenty-first century.NC: Intercultural Associates, Inc.

15. Ferrell, Hirt, Ferrell (2008). Business: A changing world. McGraw-Hill, Boston.

16. Flatley, M., Rentz, K., \& Lentz, P. (2012). Business communication (2 ${ }^{\text {nd }}$ ed.) New York: McGraw-Hill.

17. Friedman, T. L. (2005). The world is flat: A brief history of the twenty-first century. New York: Farror, Straus and Giroux.

18. Florida, Richard and Gary Gates (2001). Technology and Tolerance: the Importance of Diversity to HighTechnology Growth. Washington, D.C.: The Brookings Institution.

19. Garvin, D. A. (1993). "Building a Learning Organization.” Harvard Business Review 71(4), 71-91.

20. Giroux, H. (2004). Cultural studies and the politics of public pedagogy: Making the political pedagogical. Parallax, 10(2), 73-89.

21. Grimes D., \& Richard, O. (2003). Could communication form impact organizations" experience with diversity? Journal of Business Communication, Vol. 40, No. 1, pp. 7 - 27.180, 82, 84.

22. Gupta, S. (2008, October). Mine the Potential Of Multicultural Teams. HR Magazine, 53(10), 79-80, 82, 84.

23. Hannay, M., \& Fretwell, C. (2011). The higher education workplace: meeting the needs of multiple generations. Research in Higher Education Journal, 10, 1-12.

24. Hansen, F. (2003). Diversity's business case doesn't add up. Workforce, pp. 28-32.

25. Hellriegel \& Slocum (2009). Organizational Behavior. Southwestern Publishing, OH.

26. Hunt, K... (2011, March). Embracing diversity. Journal of Property Management, 76(2), 29-33. Retrieved June 17, 2011, from ABI/INFORM Global. (Document ID: 2371411131).

27. Jandit, F. E. (2003). An introduction to intercultural communication: Identities in a global community. Thousand Oaks, CA: Sage Publications.

28. Kanu, K. (2008, November). The new workforce. Black Enterprise, 39(4), 68. Retrieved June 24, 2011, from ABI/INFORM Global. (Document ID: 1586944101).

29. Lauring, J. (2011). The social order of interaction in international encounters. Journal of Business Communications, 48, $231-255$.

30. Lieber, L. (2009). The Hidden Dangers of Implicit Bias in the Workplace. Employment Relations Today, 36(2), 93. Retrieved June 23, 2011, from ABI/INFORM Global. (Document ID: 1811109241).

31. Martin, J., \& Nakayama, T. (2007). Intercultural communication in contexts (4th ed.). New

32. Mulkeen, D. (2008). How can the HR team improve internal communication? Strategic HR Review, 7(2), 42. Retrieved June 20, 2011, from ABI/INFORM Global. (Document ID: 1603677461).

33. Nagourney, E. (2008, March 18). East and West part ways in test of facial expression. New York.

34. Ober, S. (2006). Contemporary Business Communication ( $6^{\text {th }}$ Ed). Boston: Houghton Mifflin Company.

35. Roberson, Q.M., \& Park, H.J. (2007). Examining the link between diversity and performance: The effects of diversity reputation and leader racial diversity. Group and Organization Management, 32(5), 548-568.

36. Sadri, Golnaz \& Tran, Hoa (2002) "Managing your diverse workforce through improved communication", Journal of Management Development, Vol. 21 Issue: 3, pp.227-237.

37. Schermerhorn, Hunt, \& Osborn (2007). Organizational behavior. Wiley Publishers, NJ.

38. Thomas, D.A., \& Ely, RJ. (1996). Making differences matter: A new paradigm for managing diversity. Harvard Business Review, 74(5), 79-90.

39. Tuleja, E. A. (2008). Intercultural communication for business (2nd ed.). Mason, OH: Cengage SouthWestern Publishing. U.S. Census Bureau (2007), "National Population Projection (SummaryFiles),"'availableonliat-http://www.census.gov/population/www/projections/natsum-T1html.

40. U.S. Census Bureau (2001). USA Statistics in Brief-1990 and 2000 Census Race and Hispanic Data. http://www.census.gov/statabwww/partla.html>U.S. Census Bureau, Administrative and Customer Services Divisions, Statistical Compendia Branch.

41. Weaver, Vanessa J. (2001). "What These CEOs and Their Companies Know About Diversity." Business Week, September 10, 2001, Special Section. 